\title{
NOTES AND CORRESPONDENCE
}

\section{Climatic Jump : A Hypothesis in Climate Diagnosis}

\author{
By Ryozaburo Yamamoto, Tatsuya Iwashima, Sanga-Ngoie Kazadi \\ Laboratory for Climatic Change Research, Kyoto University \\ 17-1, Ohmine-cho, Kitakazan, Yamashina-ku, Kyoto 607, Japan
}

and

\section{Makoto Hoshiai}

\author{
Physics Laboratory, Aichigakuin University, \\ 12 Araike, Iwasaki, Nisshin-cho, Aichi-gun, Aichi-ken 470-01, Japan \\ (Manuscript received 6 September 1985, in revised form 15 October 1985)
}

\section{Introduction}

Climatic system is a non-linear physical system under external forcing such as solar heating. In his nondeterministic theory of climatic change, Lorenz (1968, 1976) noticed that non-linear physical system has generally transitivity and intransitivity, the latter of which has statistics dependent of initial conditions. The system changes from transitivity to intransitivity by change of parameters in the governing equations. When the parameter change is not so much, the system becomes of almost intransitivity, in which the statistics for finite time interval vary from interval to interval. Lorenz (1976, 1984) emphasized the potential importance of the almost intransitivity in climatic change, although the existence was neither yet confirmed in sophisticated numerical model of the climate or the atmosphere, nor in analysis of actual climate data.

Iwashima et al. (1985) has recently confirmed a possibility of existence of multiple stable solutions based on a time-space spectral model of the atmosphere under seasonal thermal forcing. Their finding does appear to support the Lorenz' idea, although the detailed discussions are now being prepared on the model behaviors. Therefore, it is now worthwhile to attempt data analysis to de- tect some evidence of almost intransitivity or intransitivity. Noticing the significant seasonal forcing, Lorenz (1976) suggested that transition from a regime to another in almost intransitivity should not occur intra-seasonally, but interannually. This implies that some abrupt change would appear in interannual variability of climate, if regime transition would happen in almost intransitivity.

In Unusual Weather Report (Japan Meteorological Agency, 1984), an abrupt change like a jump is noticed around 1950 for seasonal mean air temperature in Japan. This notice makes the present authors to try data analysis with respect to "Climatic Jump" or abrupt change of interannual mean level of climate. In the most climate diagnoses, data analyses are usually performed based on the assumption of continuous change (Mitchell et al. 1966). Any attempt to analyze such change as jump is not yet made so far as the present authors know, and there is no established procedure of jump analysis, except Yao's (1984). Our concerns are to deal with the abrupt climatic change of long (a few decadal) time-averaged state. We can tentatively assume that the climatic "jump" can be statistically defined as the difference between two consecutive averages over a few decades, which is beyond a summation of the noise level for the respective periods. In 
any case, survey of climatic jump in the present paper is made only for the surface air temperature rather qualitatively. Quantitative definition and quantitative treatment of the "climatic jump" will be performed in a separate paper to be issued in near future.

\section{Abrupt Change of Time Mean Level of Surface Air Temperature}

The abrupt change of time mean level mentioned in the previous section can be seen in Fig. 1 reproduced from Unusual Weather Report (Japan Meteorological Agency 1984). This is a spatial average over 23 stations, the locations of which are shown by black dots in Fig. 2. It should be noted that the abrupt change of mean values can be seen even in such places where any effects of the urbanization cannot be expected. Although year-to-year variablity is remarkable, it is seen that the level averaged over a few years does abruptly change around the year 1950 , and that the 30 -year mean of winter temperture is $2.11^{\circ} \mathrm{C}$ for $1922-1951$ and 2.78 ${ }^{\circ} \mathrm{C}$ for 1951-1980. Taking account of the climate noise (Leith 1973; Madden and Shea 1978), it should be examined whether the difference between both 30 -year means would be significant or not. The noise of monthly mean air temperature is estimated as $0.5^{\circ} \sim$

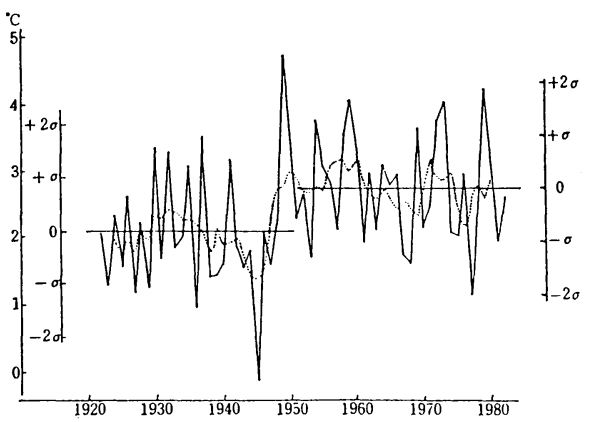

Fig. 1 Interannual variability of surface air temperature of winter averaged over the 23 stations indicated in Fig. 2 . $\sigma$ on the ordinate means the standard deviation. 5-year moving average is shown by dotted line, and 30-year mean by horizontal one. This is reproduced from Unusual Weather Report (Japan Meteorological Agency, 1984), with permission of Japan Meteorologicol Agency.

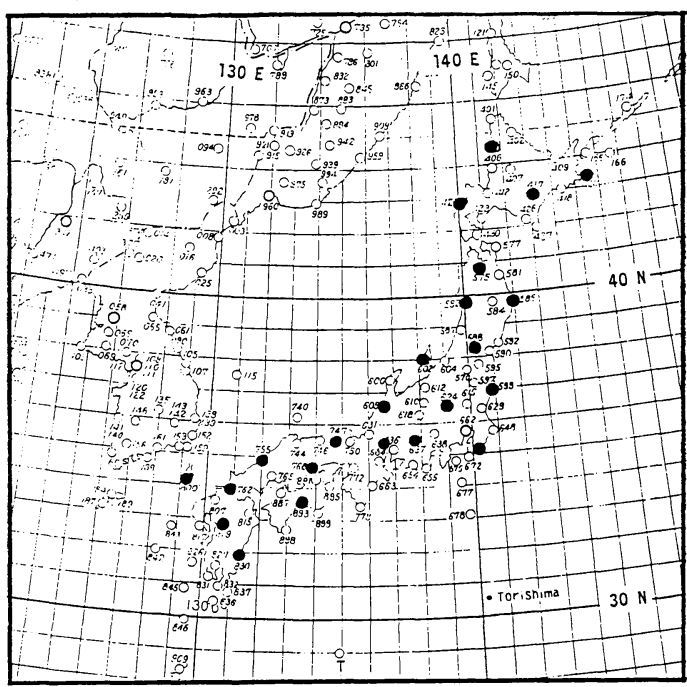

Fig. 2 Geographical locations of the 23 stations (shown by black dots), the data of which are taken for the interannual variability in Fig. 1.

$0.8^{\circ} \mathrm{C}$ for winter of northern Japan (Yamamoto et al. 1985a) and the noise in monthly mean at the other stations on Japan can be assumed to be $1^{\circ} \mathrm{C}$ at most. The noise of 30 year mean of 3-month mean at a station can be assumed to be $1 / \sqrt{3 \times 30}$ of noise in monthly mean, or to be $0.1^{\circ} \mathrm{C}$ at most. The noise in spatial mean or average over a number of stations must be reduced more or less, depending on the averaging extent (Yamamoto et al. 1985b). The jump of winter mean temperature averaging over 23 stations around the year 1950 is sufficientry greater than the estimated noise, and it can be stated that this jump is not accidental, but of physical reality.

Year-to-year variations of seasonal meen surface air temperature in the Arctic region $\left(65^{\circ} \sim 85^{\circ} \mathrm{N}\right)$ are given by Kelly et al. (1982). From their paper, the departure of winter temperature from 15 years $(1946 \sim 1960)$ is reproduced in Fig. 3. The average over two decades of the 1930 's is about $0.5^{\circ} \mathrm{C}$ and that over 1950 and 1960 decades about $0.0^{\circ} \mathrm{C}$. An abrupt change of the averages like a jump is clearly seen about the year 1950 , with sense opposite to that of Japanese temperature in Fig. 1.

Diaz and Quayle (1980) noted, in their investigation of climatic change in the United 


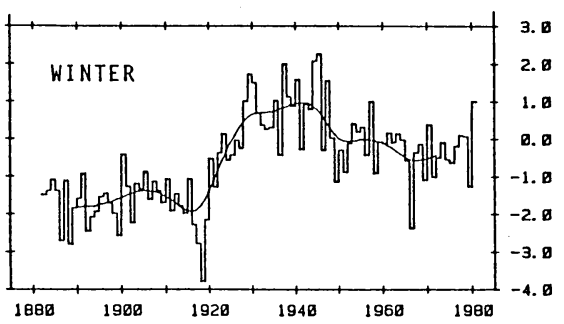

Fig. 3 3-month mean temperature of winters as departures from the reference period 1946-1960 over the Arctic $\left(65-85^{\circ} \mathrm{N}\right)$. This is reproduced from Kelly et al. (1982), with permission of the American Meteorological Society.

the United State for 83 years, the two abrupt changes of temperature around 1920 and 1950, without any particular interpretation for the abrupt changes. Simultaneous occurrence of abrupt change, irrespective of the sense, in the United States, Japan and the Arctic suggests that the temperature jump in question here is not local nor regional, but rather hemispherical or global phenomena.

Diaz and Quayle (1980) noticed that the temperature averaged over the three decades of 1920,1930 and 1940 is lower, in the eastern United States, than that in the next three decades, and higher in the western part. Together with the opposite sense in Japan and the Arctic, this fact shows the jump considered here has not necessarily the same sence everywhere. When transition from a regime to another one in almost intransitivity, any change of the global mean temperature is impossible without any change of global radiation budget. Therefore, it is reasonable to presume that the temperature jump in question here has generally some geographical distribution with the same or opposite sense, except case of changing external forcing or cloud distribution influencing the global heat balance.

\section{Concluding Remarks}

Lorenz' (1968, 1976) nondeterministic theory of climatic change has been supported by recently developed space-time spectral model of the atmosphere by Iwashima et al. (1985). This modelling makes the present authors to survey empirically any abrupt climatic change like jump in interannual variability, and temperature jump could be detected around the year 1950 in various region over the globe, with positive or negative sense.

Although some evidence of abrupt change occurring almost simultaneously with the temperature jump could be found in the time series of precipitation and sunshine duration given in Unusual Weather Report (Japan Meteorological Agency, 1985), their description will be given in separate paper to be issued in near future, after estimate of their climatic noise. Together with quantitative analysis of the jumps, it should be examined whether any triggering action would appear or not for regime transition in almost intransitivity.

\section{Acknowledgement}

The present work was partly supported by the Scientific Fund from the Ministry of Education, Science and Culture.

\section{References}

Diaz, H.F. and R. G. Quayle, 1980: The climate of the United States since 1895: Spatial and temporal changes. Mon. Wea. Rev., 108, 249266.

Iwashima, T. and R. Yamamoto, 1985: Time-space spectral general circulation model, Part I. Timespace spectral model of low-order barotropic system with periodic forcing. J. Meteor. Soc. Japan, (submitted).

Japan Meteorological Agency, 1984: Unusual Weather Report (in Japanese), Office of Printing, Ministry of Finance, Tokyo, $294 \mathrm{pp}$.

Kelly, P. M., P. D. Jones, C. B. Sear, B. S. G. Cherry and R.K. Tavakol, 1982: Variations in surface air temperature: Part 2. Arctic regions, 18811980. Mon. Wea. Rev., 110, 71-83.

Leith, C.E., 1973: The standard error of time averaged estimates of climate means. J. Appl. Meteor., 12, 1066-1069.

Lorenz, E. N., 1968: Climatic determinism. Meteor. Monogr. 8, No. 30, 1-3.

- 1976: Nondeterministic theories of climatic change. Quatern. Res., 6, 495-506.

- 1984: Some aspects of atmospheric predictability. Problems and Prospects in Long and Medium Range Weather Forescasting ed. by D. M. Burridge and E. Källen, Springer. pp. 1-20.

Madden, R. A. and D. J. Shea, 1978: Estimates of the natural variability of time-averaged temperatures over the United States. Mon. Wea. Rev., 106, 1695-1703.

Mitchell, J.M., Jr., B. Dzerdzeevskii, H. Flohn, 
W. L. Hofmeyr, H. H. Lamb, K. N. Rao and C. C. Wallèn, 1966: Climatic change, WMO Tech. Note, No. 79, WMO, Geneva, 79 pp.

Yamamoto, R., T. Iwashima, Sanga N. K. and M.

Hoshiai, 1985a: An estimate of climatic noise. J. Meteor. Soc. Japan, 63, 1147-1156.

Estimate of climatic noise in monthly mean tem- perature. J. Meteor. Soc. Japan. (to be submitted).

Yao, Y.C., 1984: Estimation in the presence of noise of a signal which is flat except for jumps. Statistical Signal Processing, ed. by E.J. Wegman and J.G. Smith. Marcel Cekker, New York. pp. 107-176.

\title{
気候ジャンプ一気候診断の一つの仮説
}

\section{山 元 龍三郎 - 岩 嶋 樹 也 - Sanga-Ngoie Kazadi}

京都大学理学部気候変動実験施設

\author{
星 合誠
}

愛知学院大学教養部*

\footnotetext{
* 愛知県愛知郡日進町大字岩崎阿良池 12 （开470-01） 愛知学院大学教養部物理学教室
} 